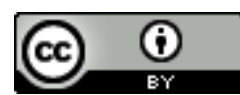

Esta obra está sob o direito de Licença Creative Commons Atribuição 4.0 Internacional.

\title{
SAÚDE MENTAL: \\ TRABALHO DOCENTE E O ADOECIMENTO DOS PROFESSORES
}

\author{
Betijane Soares de Barros $^{40}$ \\ Andrea Marques Vandelei Fregadolli ${ }^{41}$ \\ Izeni Texeira Pimentel ${ }^{42}$ \\ Cleidejane Soares de Barros ${ }^{43}$ \\ Rubiana de Omena Gusmão Moreno da Rocha ${ }^{44}$
}

\begin{abstract}
RESUMO
Neste trabalho identificar os principais fatores que contribuem para o adoecimento mental do professor. Entender a realidade do professor nas do mundo atual, assim como as condições de trabalho afetam e adoecem os docentes, assim como permite criar estratégias para evitar esse cenário trágico nos respectivos locais de trabalho. Esse estudo trata-se de um estudo qualitativo do tipo exploratório e bibliográfico, onde identificou-se que a excessiva carga de trabalho e número dos alunos, seguida da falta de interesse dos mesmos, e um ambiente de trabalho que não promova boas condições e estruturas físicas foram os principais fatores identificados que permite estabelecer uma relação com o adoecimento psicológico decorrente da situação de trabalho. O trabalho contribuirá no desenvolvimento de novos pensamentos para novas alternativas e soluções, para os conflitos que o professor poderá ter em seu trabalho educacional, e para a prevenção do seu adoecimento psicológico. Portanto, foi possível observar que existe uma grave crise em relação à saúde mental do professor, e que se precisa investir em saúde mental e em qualidade de vida para que seus docentes sejam profissionais mais motivados e sadios.
\end{abstract}

Palavras-chave: Saúde mental. Professor. Trabalho. Adoecimento.

\footnotetext{
${ }^{40}$ bj-sb@hotmail.com

41 deadoutorado@hotmail.com

42 izenitpimentel@hotmail.com

43 dr.csbarros@hotmail.com

${ }^{44}$ rubianaomena@hotmail.com
} 


\section{INTRODUÇÃO}

$\mathrm{O}$ adoecimento mental dos professores é um grave problema nos tempos atuais que compromete diretamente a qualidade de ensino. Identificar os fatores que contribuem para o adoecimento mental é um alerta para a sociedade conhecer a realidade deste profissional e adotar medidas que revertam esse cenário, que compromete o papel social do professor e, consequentemente, da sociedade (FERNANDES, M. A. et al. 2018).

O compromisso do professor está pautado principalmente nas relações humanas e na ética. O professor é um ser que pertence à sociedade, portanto influencia e é influenciado, constrói e é construído, incentiva e encoraja os alunos, contribuindo com novos pontos de vista sobre os quais o aluno não enxergou, estimulando novos saberes (MINISTÉRIO DA ECONOMIA, BRASIL, 2018).

O trabalho tem caráter discursivo, tipo de pesquisa de revisão bibliográfica exploratória, onde a pesquisa significa procurar respostas para os questionamentos propostos. Resgatar a produção científica disponível em livros, nas bases de dados de livre acesso e também em revistas científicas. Identificar e entender através destas ferramentas de como estes e outros fatores interferem na saúde do professor, contribuirá para refletir em medidas eficazes que promoverão qualidade de vida e um melhor desempenho destes profissionais, visto que há poucas referências teóricas acerca de trabalhos sobre a saúde mental do professor (TOSTES et al. 2018).

\section{MÉTODOLOGIA}

Trata-se de uma revisão bibliográfica, que seguiu as seguintes etapas: definição do tema; seleção da pergunta norteadora e escolha da estratégia de busca; descritores e bases de dados mais eficazes no levantamento das publicações; escolha dos critérios de inclusão e exclusão; identificação dos estudos pré-selecionados e selecionados por meio da leitura dos agentes indexadores das publicações, como resumos, palavras-chave e títulos, bem como a organização dos estudos préselecionados e a identificação dos estudos selecionados.

\section{COMO O ATUAL TRABALHO DOCENTE ADOECE OS PROFESSORES?}

Como observado a categoria docente enfrenta transformações da sociedade que interfere no seu trabalho. "A sociedade a qual vivemos possui condições reais de ambiente que afetam a qualidade de vida dos trabalhadores podendo vir a contribuir e fazer com que o trabalho seja gerador de sofrimento e não de prazer" (MACEDO, E.B. 2018).

A relação da saúde com o trabalho docente pode ser entendida pelas ciências sociais através da categoria processo de trabalho. $\mathrm{O}$ processo de produção capitalista possui um duplo sentido, abstrato como processo de valorização e concreto como processo de trabalho, a produção de mercadorias. $\mathrm{O}$ processo de trabalho manifesta-se através de seus três elementos: o objeto, que é matéria a ser transformada; a tecnologia utilizada para a transformação do objeto; e a atividade desenvolvida pelo professor. A articulação complexa dos elementos constitutivos do processo de trabalho, segundo uma dada lógica de 
organização e divisão do trabalho, determina a ocorrência de cargas de trabalho específicas para cada tipo de atividade produtiva, que vão modelar o desgaste psicobiológico dos professores (LOPES, A. et al., 2014).

Essa exigência de trabalho da sociedade atual, que se torna cada vez mais produtivista, competitiva e excludente, impacta nos professores gerando também atitudes individualistas e até mesmo competitivas, além de gerar um excesso de estresse devido às exigências profissionais no ambiente e fora dele, levando uma sobrecarga de trabalho para casa, tornandoos mais vulneráveis a serem vítimas dos problemas em saúde mental (OMS. 2020).

$\mathrm{Um}$ dos principais fatores de adoecimento profissional é a solidão, que está pautada na falta de apoio mútuo entre os profissionais, não obtendo troca de experiência, mas um individualismo na prática docente, tendo uma relação de trabalho que não é focada na sinceridade, que não promove uma expressão de pontos de vista divergentes para o crescimento mútuo. A solidão pode ser provida também de um abandono por parte do corpo diretivo das faculdades não oferecendo apoio técnico pela falta de reconhecimento e/ou pela concorrência com outros meios de transmissão de informação e cultura. $\mathrm{O}$ estresse também é um fator responsável pelo exagerado número de professores que se afastam da sala de aula, e a presença desse sentimento dá lugar à vivência do sofrimento psíquico na atividade docente, ameaçando desta forma a saúde dos professores (FERREIRA, R.C. et al., 2015).

$A$ relação que se exerce com o trabalho acadêmico pode ser geradora de doença ou um local onde se possam descarregar tensões do dia-a-dia. Descarregar as tensões do dia-a-dia é uma das estratégias de enfrentamento seja de forma coletiva ou individual que ameniza o sofrimento, transformando-o em força que propicia mudança. Essa força positiva depende da estrutura psíquica do professor, que é formada pela história individual e como ele se relaciona com os colegas de trabalho. O sofrimento que o trabalho proporciona e torna doença, parte do princípio do quanto o professor tenta adaptar à realidade sofrida do trabalho com os sonhos e desejos que tem sobre ele e as defesas coletivas fracassam. Os surtos psicóticos e a formação das neuroses dependem da estrutura da personalidade que a pessoa desenvolve desde o início da sua vida, chegando a certa configuração relativamente estável, após o período de ebulição da adolescência (FERREIRA, E. B., VENTORIM, S.; CÔCO, V., 2010).

Apesar dessas particularidades na estrutura de personalidade do indívíduo que favorecem ou não o surgimento dos distúrbios mentais, diz que o processo de adoecimento dos professores está intimamente ligado ao sofrimento no trabalho, que por sua vez, está relacionado com a organização do trabalho e conteúdo da tarefa: [...] "quanto mais à organização do trabalho é rígida, mais a divisão do trabalho é acentuada, menor é o conteúdo significativo do trabalho e menores são as possibilidades de mudá-lo. Correlativamente, o sofrimento aumenta" (FERREIRA, C. M., 2011).

Os processos de saúde-doença dos trabalhadores docentes são compreendidos de distintas formas e tal variabilidade relaciona-se aos diferentes enfoques e perspectivas teóricas adotadas na área de Saúde e Trabalho. De modo geral, podemos afirmar que tais processos são compreendidos ora a partir da ênfase nos aspectos biológicos, ora nos aspectos 
psicológicos, ora nos aspectos psicossociais, ora nos aspectos sócio institucionais (FERNANDES, M. A. et al. 2018).

O adoecimento físico e psicológico do professor é uma das consequências de más condições de trabalho mais destacadas na literatura. Entretanto, a saúde do professor ainda não recebe o lugar de destaque que merece nas discussões sobre a educação e a profissão docente. Por ser um profissional que tem a função de cuidar do outro, o professor termina esquecendo-se de si e de sua saúde. "Sintomas de adoecimento são negados ou minimizados; apenas quando um problema atinge um patamar de severidade elevada é que se atenta para a sua existência”. Em decorrência disso, o adoecimento do professor ao invés de ser analisado como algo diretamente relacionado com sua profissão, é distanciado da realidade do trabalho e considerado como um problema de cunho individual seja por uma inadequação do professor ou uma dificuldade puramente pessoal (FERREIRA, R.C. et al., 2015).

Por isso, é necessário que a preocupação com as condições do trabalho escolar volte-se também para a saúde dos professores: para que se permita um ótimo desenvolvimento do processo de aprendizagem e melhor qualidade do ensino, é necessário o bem estar integral, físico, psíquico e social de toda a com unidade educativa (LOPES, A. et al., 2014).

\section{CONDIÇÕES DE TRABALHO DO PROFESSOR}

As condições de trabalho do professor podem variar de acordo com o tipo da instituição (pública ou privada) e ainda de acordo com o segmento institucional (educação infantil, ensino fundamental, ensino médio, ensino superior e pós-graduação). Assim como a percepção do professor é variável, frente a representação de si na sua profissão e as condições de trabalho às quais está sujeito (MACEDO, E.B. 2018).

Entende-se por subjetividade a maneira particular de cada sujeito estar no mundo, avaliar os fenômenos e relacionarse com o grupo. Ou seja, o que é bom e ruim pode variar de acordo com as opiniões, experiências e informações que cada sujeito ou grupo social possui sobre determinado fenômeno. No caso da educação, apresentase a seguir um apanhado do que tem sido consenso na literatura e pesquisas realizadas sobre a temática das condições de trabalho nesse campo, visto que essa é uma realidade atual e limitada ao território brasileiro (MINISTÉRIO DA ECONOMIA, BRASIL, 2018).

Entretanto, é escassa a literatura sobre condições de trabalho e saúde de docentes, principalmente no nível universitário, quando comparada a outras áreas trabalhistas; até pouco tempo, os estudos privilegiavam as relações entre saúde e trabalho, em contextos fabris, onde a relação entre trabalho e saúde é mais direta e os riscos à saúde são mais evidentes (TOSTES et al. 2018).

Ultimamente o trabalho docente tornou-se tema de diversos estudos, com o incentivo de formação de grupos e de redes de pesquisadores organizados para esse fim (TOSTES et al. 2018).

$\mathrm{O}$ professor, as condições de trabalho, ou seja, as circunstâncias sob as quais os docentes mobilizam as suas capacidades físicas, cognitivas e afetivas para atingir os objetiv-os da produção educacional podem gerar sobre-esforço ou hiper solicitação de suas funções 
psicofisiológicas. Se não há tempo para a recuperação, são desencadeados ou precipitados os sintomas clínicos que explicariam os índices de afastamento do trabalho por transtornos mentais. Portanto, é importante ressaltar as atuais condições de trabalho do professor e suas consequências, pois desta forma é possível criar estratégias para reduzir os índices de afastamento e adoecimento dos professores (OMS. 2020).

Dentre os fatores que se relacionam às condições de trabalho, a estrutura física da instituição ganha destaque na fala dos professores. Quanto a esse aspecto, os professores sentem-se insatisfeitos por se verem impossibilitados a realizar seu trabalho devido às barreiras estruturais (MINISTÉRIO DA ECONOMIA, BRASIL, 2018).

A precariedade da estrutura física das instituições e ausência desses recursos inviabilizam o trabalho do professor, que, por vezes, precisa lançar mão de recursos próprios para compensar esses problemas estruturais. Sob essas condições, o único elemento de ajuste é o trabalhador, que, com seus investimentos pessoais, procura auxiliar o aluno carente comprando material escolar e restringindo o seu tempo supostamente livre para criar estratégias pedagógicas que compensem a ausência de laboratórios, de salas de informática e de bibliotecas minimamente estruturadas (OMS. 2020).

Sem o mínimo de estruturação física, o trabalho docente torna-se deficiente, visto que o professor necessita ocupar parte de seu tempo para resolver problemas dessa natureza. E estrutura física refere-se aos fatores como paredes, teto e carteiras conservados; quadro e pincéis para uso do professor; ventilação e iluminação adequados; banheiros suficientes e estruturados. Além disso, incluem-se nesse aspecto ainda a existência de ambientes extraclasse como bibliotecas, refeitórios/cantinas, laboratórios para atividades práticas, entre outros (MACEDO, E.B. 2018).

Sob esta ótica, a qualidade do ensino também é afetada, devido às diversas problemáticas que surgem e desviam o foco de atuação do professor no cotidiano laboral. Dessa forma, a estrutura física torna-se um fator muito importante no tocante às condições de trabalho do professor, mantendo também uma forte relação com outro item incluído nessa temática, o material pedagógico (MINISTÉRIO DA ECONOMIA, BRASIL, 2018).

Como toda profissão, à docência tem suas especificidades quanto aos recursos materiais necessários à realização plena de suas atividades. Aqui, destacam-se os livros didáticos e paradidáticos, recursos audiovisuais como Datashow, retroprojetores, aparelhos de som e computadores, materiais de apoio que auxiliem em atividades. Gasparini, Barreto e Assunção (2005), explicam que, muitas vezes, o professor precisa buscar, através de meios próprios, suprir os déficits apresentados pelas instituições. Novas metodologias são exigidas do professor, que não dispõe de recursos para desenvolvê-las. Essa situação gera sentimentos de ineficiência, sensação de trabalho não cumprido, podendo acarretar, inclusive, problemas de saúde para o professor (TOSTES et al. 2018).

As propostas curriculares geram insatisfação para os professores, mas não apenas por "controlarem" o seu trabalho, pois ainda há um pequeno espaço de autonomia, mas muito mais pelo fato de não condizerem com as condições materiais existentes, isto é, a infraestrutura deficitária 
da instituição e a inexistência de recursos materiais necessários para concretizar o que essas propostas sugerem (OMS. 2020).

Um outro fator bastante comum de insatisfação com as condições de trabalho do professor refere-se à sobrecarga de trabalho. Os professores relacionam a sobrecarga de trabalho a diversos aspectos, tais como a quantidade elevada de alunos por turmas, trazendo como consequência falta de tempo para planejar e para executar bem suas atribuições, elevada carga horária e grande número de atividades a desenvolver. Essa realidade de sobrecarga não se restringe somente à educação básica (MACEDO, E.B. 2018).

No ensino superior, os professores são cada vez mais pressionados a produzirem, ou seja, apresentar produtos de diversos formatos: aulas, orientações, artigos científicos, eventos e projetos de extensão. Assim, prioriza-se a quantidade de produções e não a qualidade. Nas duas últimas décadas, principalmente, o trabalho docente do ensino superior tem passado por um processo crescente de precarização. Essa situação fundamenta-se fortemente no ínfimo crescimento do quadro de professores na educação superior privada, quando comparada com a rede de ensino superior pública. Não é difícil perceber que esse dado gera uma sobrecarga de trabalho para os professores que trabalham nas instituições privadas de ensino superior, afetando negativamente as condições de trabalho docente (FERNANDES, M. A. et al. 2018).

Além dessas dificuldades enfrentadas pelos professores, a sobrecarga citada também tem relação com as mudanças sociais ocorridas nos últimos tempos, gerando novas expectativas da sociedade quanto à escola e à figura do professor. Expectativas estas que nem sempre podem ser atendidas devido à própria organização e estrutura do sistema educacional. A isto se acrescenta o fato de que a gestão democrática. Ou seja, muitas são as atribuições delegadas aos professores da atualidade, que não se percebem estimulados e em terreno favorável para realizar tais exigências (MINISTÉRIO DA ECONOMIA, BRASIL, 2018).

Numa sociedade capitalista, o salário apresenta-se para os profissionais de qualquer área como um fator de atratividade ou repulsa pelas atividades que se lhe oferecem. Para a categoria docente, não é diferente. Muitos teóricos apontam o salário do professor como um dos principais fatores de insatisfação profissional. Em alguns casos, a insatisfação com o salário pode chegar a níveis extremos, levando até ao adoecimento e/ou abandono da profissão. Os salários são considerados baixos quando comparados às dificuldades enfrentadas pelos professores no seu cotidiano profissional (MINISTÉRIO DA ECONOMIA, BRASIL, 2018).

Muitos estudos apontam que os professores não se percebem recompensados financeiramente pelo trabalho que desempenham. Essa realidade é observada quando se direciona a atenção para a rede pública de ensino e, principalmente, na educação básica, sendo até motivo para a exoneração. $\mathrm{E}$ diante dessa realidade, até os comportamentos de confronto e contestação da autoridade dos alunos em relação aos professores acabam sendo afetados. Isso porque uma das razões para esse tipo de comportamento é a percepção de uma superioridade econômica daqueles em relação a este. Ou seja, os alunos partem de um preconceito de que não podem receber conhecimentos e valores de alguém que, na sua concepção, seria 
socioeconomicamente inferior a eles (OMS 2020).

Com a realidade de crescente violência urbana, a segurança passa a ser um outro fator de grande importância para o desempenho da função docente, passando a se incluir nas condições de trabalho do professor. O fenômeno da violência "tem se intensificado na sociedade e a instituição de ensino não fica de fora dessa realidade, e invertidamente, na contramão do seu papel, traz sensação de desconforto e de insegurança". Esses sentimentos são compartilhados por todos os membros que compõem a comunidade educacional e, em especial, pelo professor, que necessita realizar a sua função social independentemente do contexto em que está inserido (TOSTES et al. 2018).

O problema da violência nas instituições tem sido um dos grandes desafios para equipes gestoras e demais profissionais da educação. Esse fenômeno tem crescido nos últimos anos e se tornado uma realidade que vem desafiando os educadores, trazendo medo aos ambientes de aprendizagem, comprometendo a qualidade da aprendizagem. Apesar de a violência ser um fenômeno generalizado em vários setores sociais, os problemas que dela decorrem é bastante observado nas instituições. Não que se queira com isso transmitir um discurso preconceituoso de cunho classista, mas não se pode fugir das evidências que se acompanham diariamente sobre a violência marcante das zonas periféricas das grandes cidades (LOPES, A. et al., 2014).

No tocante às instituições, sabe-se que elas não possuem a segurança adequada. Professores e demais membros estão vulneráveis à violência de, pelo menos, duas direções diferentes: dos atores externos (aquelas pessoas que não possuem vínculo com a instituição) e dos atores internos (sujeitos que possuem vínculo com a instituição). Neste contexto, deparamonos com uma forma de sociabilidade, a violência, na qual se dá a afirmação de poderes legitima dos por um determinada norma social, o que lhe confere a forma de controle social: a violência configura-se como um dispositivo de controle, aberto e contínuo (MACEDO, E.B. 2018).

A violência seria a relação social de excesso de poder que impede o reconhecimento do outro - pessoa, classe, gênero ou raça - mediante o uso da força ou da coerção, provocando algum tipo de dano, configurando o oposto das possibilidades da sociedade democrática contemporânea. $\mathrm{Na}$ atualidade, a violência passa por um processo de banalização, tornando-se muito comum encontrar situações de violência física e verbal dentro das salas de aula. Alunos praticam atos de violência contra o professor, que se vê em estado de inércia diante de ameaças e até mesmo da concretização da violência (FERREIRA, R.C. et al., 2015).

Uma pesquisa realizada demonstra que, apesar de o principal tipo de violência estar relacionado aos conflitos entre alunos, as agressões verbais e físicas praticadas pelos alunos contra o professor e as ameaças de agressão física também se destacam nos documentos analisados. Toda essa situação torna o trabalho do professor difícil de ser realizado plenamente. A qualidade do ensino é prejudicada, pois segurança e bemestar são fatores que se incluem nas condições de trabalho do professor (FERNANDES, M. A. et al. 2018). 


\section{CONCLUSÃO}

Identificamos os principais fatores que interferem no comprometimento da saúde mental dos professores.

Entretanto, é importante ressaltar que alguns fatores nem sempre dependem exclusivamente das instâncias da instituição, tais como a motivação do aluno e valorização social da profissão. Os professores são corresponsáveis na mudança desses fatores, pois a motivação do aluno depende, entre outros aspectos, da motivação do professor, bem como a valorização social do professor, que muitas vezes não é observada nem mesmo no seu próprio discurso. Porém, as representações que os professores entrevistados neste trabalho partilham sobre as condições de trabalho na faculdade, comungam de uma representação negativa, considerando que as condições de trabalho são ruins ou insuficientes para o desempenho do seu trabalho.

A relação entre as condições de trabalho do professor e saúde mental foi visível, e os professores necessitam urgentemente de recursos que lhes proporcione melhores condições de trabalho, e assim tenha uma melhor qualidade de vida. Sendo assim, quanto melhor as condições de trabalho, mais qualidade teríamos na educação.

O sofrimento psíquico dos professores pode se tornar um caso de saúde pública, devido ao abandono deste tema na profissão que ocorre no âmbito institucional, espera-se que esse trabalho promova um pensamento crítico ao leitor de forma que o mobilize em prol dos docentes, para que cada vez mais possamos dobrar a atenção à saúde do professor que tem uma importante missão de ensinar, pois a melhoria da educação brasileira depende da melhoria da qualidade do trabalho do professor.

\section{REFERÊNCIAS}

FERNANDES, M. A. et al. Transtornos mentais e comportamentais em trabalhadores: estudo sobre os afastamentos laborais. Rev Esc Enferm USP, v. 52, n. e03396, p. 1-8, 2018.

FERREIRA, C. M. Adoecimento psíquico de professores: Um estudo de casos em escolas estaduais educação básica numa cidade mineira. Pedro Leopoldo, 2011.

FERREIRA, E. B., VENTORIM, S.; CÔCO, V. A condição do trabalho docente no Espírito Santo. In: VIII Seminario Internacional Red Estrado - UCH -

CLACSO. 2010, Lima. Anais..., Lima: Red Estrado; Universidad de Ciencias y Humanidades; CLACSO, v. 1, p. 1-15, 2010.

FERREIRA, R.C. et al. Transtorno mental e estressores no trabalho entre professores Universitários da área da saúde. Trab. Educ. Saúde, Rio de Janeiro, v. 13, supl. 1, p. 135-155, 2015.

\section{LOPES, A. et al. Trabalho Docente e} Formação Políticas, Práticas e Investigação: pontes para a mudança. Edição: CIIE - Centro de Investigação e Intervenção Educativas, 2014.

MACEDO, E.B. Processos perceptivos e a dinâmica comportamental do professor frente ao exercício da docência - conexões com Saúde mental. Revista Humanidades e Inovação, v.5, n. 3, p. 310 - 317, 2018. OMS. Saúde mental depende de bem-estar físico e social, diz OMS em dia mundial. ONUBR 10 de out. de 2006. Disponível 
em: <https://nacoesunidas.org/saudemental-depende-de-bem-estar-fisico-esocial-diz-oms-em-dia-mundial/amp/> . Acesso em 10 de fev. de 2018.

TOSTES et al. Sofrimento mental de professores do ensino público. Saúde Debate, v. 42, n. 116, p. 87-99, 2018.

Transtornos mentais e comportamentais afastaram 178 mil pessoas do trabalho em 2017. Ministério da Economia, Brasil, 10 ago. 2018. Disponível:

<http://www.trabalho.gov.br/noticias/6588 -transtornos-mentais-e-comportamentaisafastaram-178-mil-pessoas-do-trabalhoem-2017>. Acesso em: 01 Ago 2018. 